\title{
Application of Mwp to the Great December 26, 2004 Sumatra Earthquake
}

\author{
Kenji Kanjo $^{1}$, Tomomichi Furudate ${ }^{1}$, and Seiji Tsuboi ${ }^{2}$ \\ ${ }^{1}$ Matsushiro Seismological Observatory of Japan Meteorological Agency, Japan \\ ${ }^{2}$ Institute for Frontier Research on Earth Evolution/JAMSTEC, Japan \\ (Received July 4, 2005; Revised November 21, 2005; Accepted November 22, 2005; Online published February 17, 2006)
}

\begin{abstract}
A great earthquake of Mw9.0 (Harvard) occurred off of northwestern Sumatra on December 26, 2004 (UTC), causing an unprecedented tsunami disaster. An earthquake of Mw8.6 (Harvard) then occurred on March 28, 2005 (UTC), about $160 \mathrm{~km}$ to the southeast of the December event's epicenter. The Matsushiro Seismological Observatory of Japan Meteorological Agency determined magnitudes of M8.8 and M8.7 respectively for these events using the Global Seismic Network's (GSN) Live Internet Seismic Server (LISS) data. The West Coast/Alaska Tsunami Warning Center (WC/ATWC), and the Pacific Tsunami Warning Center (PTWC) both use Mwp to rapidly evaluate moment magnitude. The WC/ATWC calculated a mean Mwp of 8.0 for the multiple event on Decmber 26, 2004. Using data from the IRIS station MAJO, we determined an Mwp of 8.5 by using a distancedependent apparent P-wave velocity ( $\alpha=0.16 \Delta+7.9 \mathrm{~km} / \mathrm{sec}$.) instead of a constant apparent $\mathrm{P}$ wave velocity $(\alpha=7.9 \mathrm{~km} / \mathrm{sec}$.), for $\alpha$ in the original equation for Mwp. The corrected Mwp value of 8.5 is much closer to the total moment magnitude of the multiple ruptures of the complex December 26 main-shock, and is useful as a first magnitude estimation to evaluate possible tsunami generation.
\end{abstract}

Key words: Mw9.0 Sumatra earthquake of 2004, tsunami disaster, tsunami information, Mwp, distancedependent correction.

\section{Introduction}

A great earthquake of Mw9.0 (Harvard) occurred off of northwestern Sumatra (3.30N, 95.96E) at 00:58:53 on December 26, 2004 (UTC) causing an unprecedented tsunami disaster. The length of the seismic dislocation area extended for over $1,000 \mathrm{~km}$ from an expanse of a tsunami source and aftershock area (Lay et al., 2005). Body wave inversions show that the dislocation consisted of multiple fractures propagating to the northwest from the epicenter, at the southeastern edge of the rupture zone (Yamanaka, 2005a; Yagi, 2005a). An Mw8.6 (Harvard) earthquake then occurred $(2.074 \mathrm{~N}, 97.013 \mathrm{E})$ at 16:09:36 on March 28, 2005 (UTC), about $160 \mathrm{~km}$ to the southeast of the December event's epicenter. The March event ruptured to the southeast from it's epicenter at the northeastern edge of it's seismic dislocation area (Yamanaka, 2005b; Yagi, 2005b). The Matsushiro Seismological Observatory of the JMA has been determining hypocenters using a Grid-search method (Furudate, 2002, 2003), and magnitudes using the average of the squared velocity amplitudes for four minutes beginning at the $\mathrm{P}$ wave arrival time (Ogahara et al., 2004) using USGS/IRIS, and BUD/IRIS LISS data. Our result for the earthquake at 00:58:53 (OT) on December 26, 2004 (UTC), is M8.8, beginning at an epicenter location of 3.49N Latitude, and 95.92E Longitude, using a fixed depth of $30 \mathrm{~km}$. For the event at 16:09:36 (OT) on March 28, 2005 (UTC), we get M8.7, beginning at an epicenter location of $1.95 \mathrm{~N}$

Copyright (c) The Society of Geomagnetism and Earth, Planetary and Space Sciences (SGEPSS); The Seismological Society of Japan; The Volcanological Society of Japan; The Geodetic Society of Japan; The Japanese Society for Planetary Sciences; TERRAPUB.
Latitude, and 96.97E Longitude, also using a fixed depth of $30 \mathrm{~km}$. Mwp provides an estimate of moment magnitude from the integrated displacement of the initial $\mathrm{P}$ waves of a broadband seismic record, or from differences of amplitude with $\mathrm{P}$ and $\mathrm{pP}$ or $\mathrm{sP}$ wave enabling very fast tsunami warnings (Tsuboi et al., 1995, 1999). The WC/ATWC and the PTWC both use Mwp to estimate moment magnitude so that they can issue Tsunami warnings as quickly as possible. We calculated an Mwp of 8.0 for the December 26, 2004 earthquake from the first peak of the integrated broadband P-wave displacement at MAJO and determined 8.2 by adding a magnitude-dependent correction (Whitmore et al., 2002). This Mwp value of 8.2 is much smaller than Harvard's $\mathrm{Mw}=9.0$ (300 to $500 \mathrm{sec}$.), and Stein and Okal's (Stein and Okal, 2005) estimate of Mw9.3 from free oscillation data (Park et al., 2005). The initial Mwp announced by the PTWC was 8.0. We calculated the seismic moment from the integrated displacement waveform for 120 seconds from the $\mathrm{P}$ wave arrival time of each earthquake, using data from the IRIS MAJO station. Using $\alpha=0.16 \Delta+7.9$, instead of $\alpha=7.9$, we get Mwp 8.5 for the December 26, 2004 event, and Mwp 8.7 for the March 28, 2005 earthquake.

\section{Hypocenter Determination}

We acquire real time data from the USGS/IRIS, and BUD/IRIS Live Internet Seismic Server (LISS), display the waveforms on a computer screen, record the data in buffered memory, and save it on disk. We then pick the P-wave arrival time using our interactive display software, and determine the earthquake's hypocenter. The waveform amplitudes are normalized by the noise level, sorted by epi- 


\title{
M9.0 Sumatra - Andaman Island Earthquake of 26 December 2004
}

\author{
LISS WL $=8.8$ (Used statlons $=8$ ) \\ LISS depth fres \\ $2004 / 12 / 26$ 0g-5 E58.2(JST), $2004 / 12 / 26$ \\ $005 E 58.2(U T 0)$ \\ $8.49 \mathrm{~N} 95.91 \mathrm{E} 71.0 \mathrm{~km}$ Reskual $1.9 \mathrm{sec}$ \\ off west coast of northern Sumatera, Indonesta \\ depth flesed \\ $2004 / 12 / 26$ 0Sc5\&58.6(JST), $2004 / 12 / 26$ \\ Doc5E-58.6(UTC) \\ $8.49 \mathrm{~N} \quad 95.92 \mathrm{E} \quad 20.0 \mathrm{~km}$ \\ off west coast of northern Sumatera, Indonesta \\ HYPOSAT 2004/12/2608E5E4B.6(JST). $2004 / 12 / 26$ \\ OC:5E4B.6(UTQ) \\ $8.41 \mathrm{k} 95.85 \mathrm{E} \quad 0.0 \mathrm{~km}$ \\ off west coast of northern Sumatera, Indonesla \\ Number of Dbserved Statlons 15

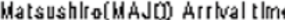 \\ $2004 / 12 / 261000751(\mathrm{JST})$ \\ Watsushiro(HAJdO) Theoretleal Árrhal tlme \\ P $2004 / 12 / 2610007: 520$ (JST) \\ S $2004 / 12 / 2610150108.9$ (JST) \\ LR $\quad 2004 / 12 / 26102228.6(\mathrm{JST})$
}
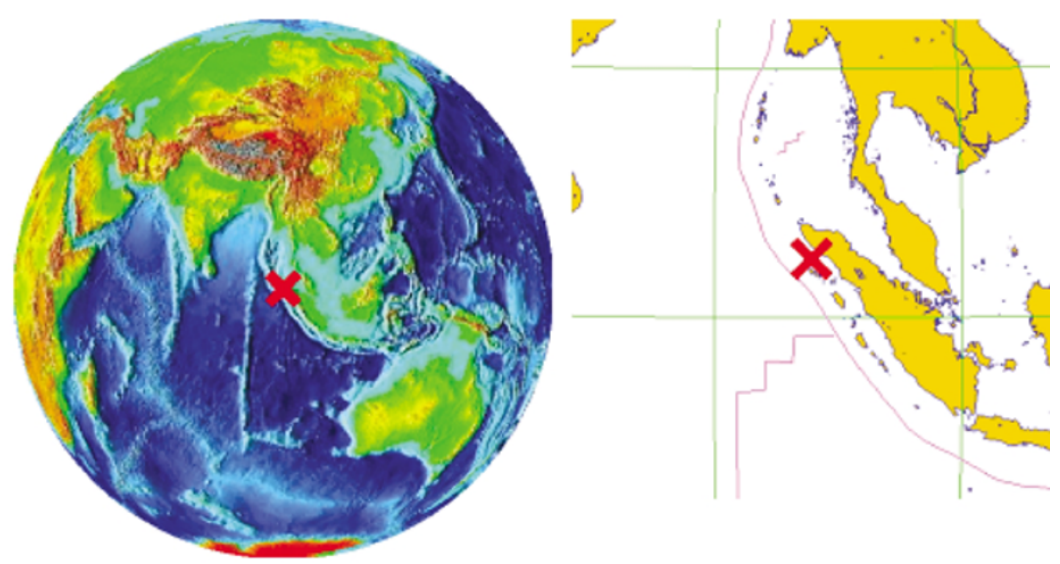

Fig. 1. Earthquake information of M9.0 Sumatra-Andaman Island Earthquake on 26 December 2004 that was determined from the grid-search method using Live Internet Seismic Server (LISS) data received at Matsushiro Seismological Observatory. The hypocenter was determined in Off West-coast of Northern Sumatra, Indonesia (origin time $=2004 / 12 / 26$ 00:58:53.6 (UTC), lat. $=3.49 \mathrm{~N}$, long. $=95.92 \mathrm{E}$, depth $=30 \mathrm{~km}($ fixed), Mw $=8.8$ ( 3 stations used)) and sent to JMA head quarter by e-mail. The epicenter is showed with a red cross in the global and regional map respectively by attached file of e-mail.

\section{M8.7 Northern Sumatra Earthquake of 28 March 2005}
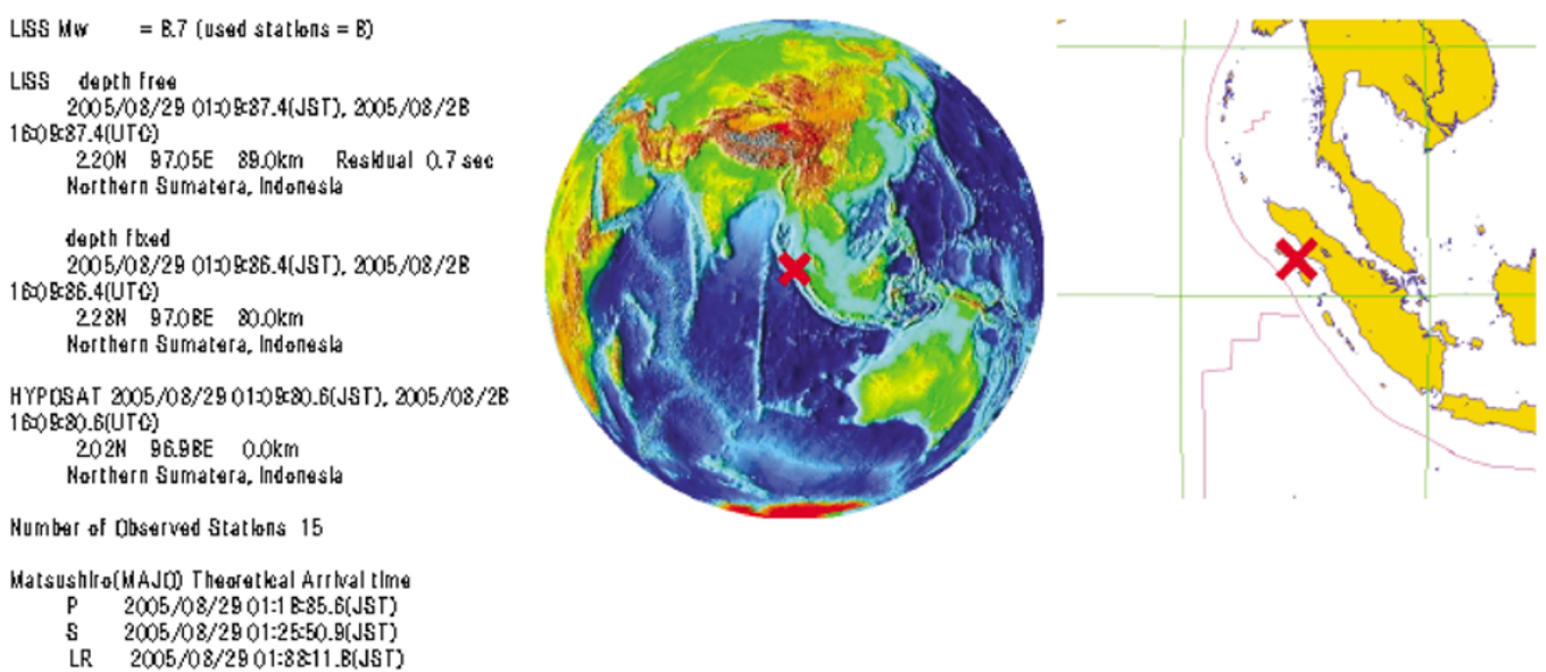

Fig. 2. Earthquake information of M8.7 Northern Sumatra Earthquake on 28 March 2005 that determined from the grid-search method using Live Internet Seismic Server (LISS) data at Matsushiro Seismological Observatory. The hypocenter was determined in Off West-coast of Northern Sumatra, Indonesia (origin time $=2005 / 03 / 28$ 16:09:36.0 (UTC), lat. $=1.95 \mathrm{~N}$, long. $=96.97 \mathrm{E}$, depth $=30 \mathrm{~km}($ fixed), Mw $=8.7(18 \mathrm{stations}$ used)) and sent to JMA head quarter by e-mail. The epicenter is showed with a red cross in the global and regional map respectively by attached file of e-mail. 


\section{4/12/26 MAJO(BHZ)}

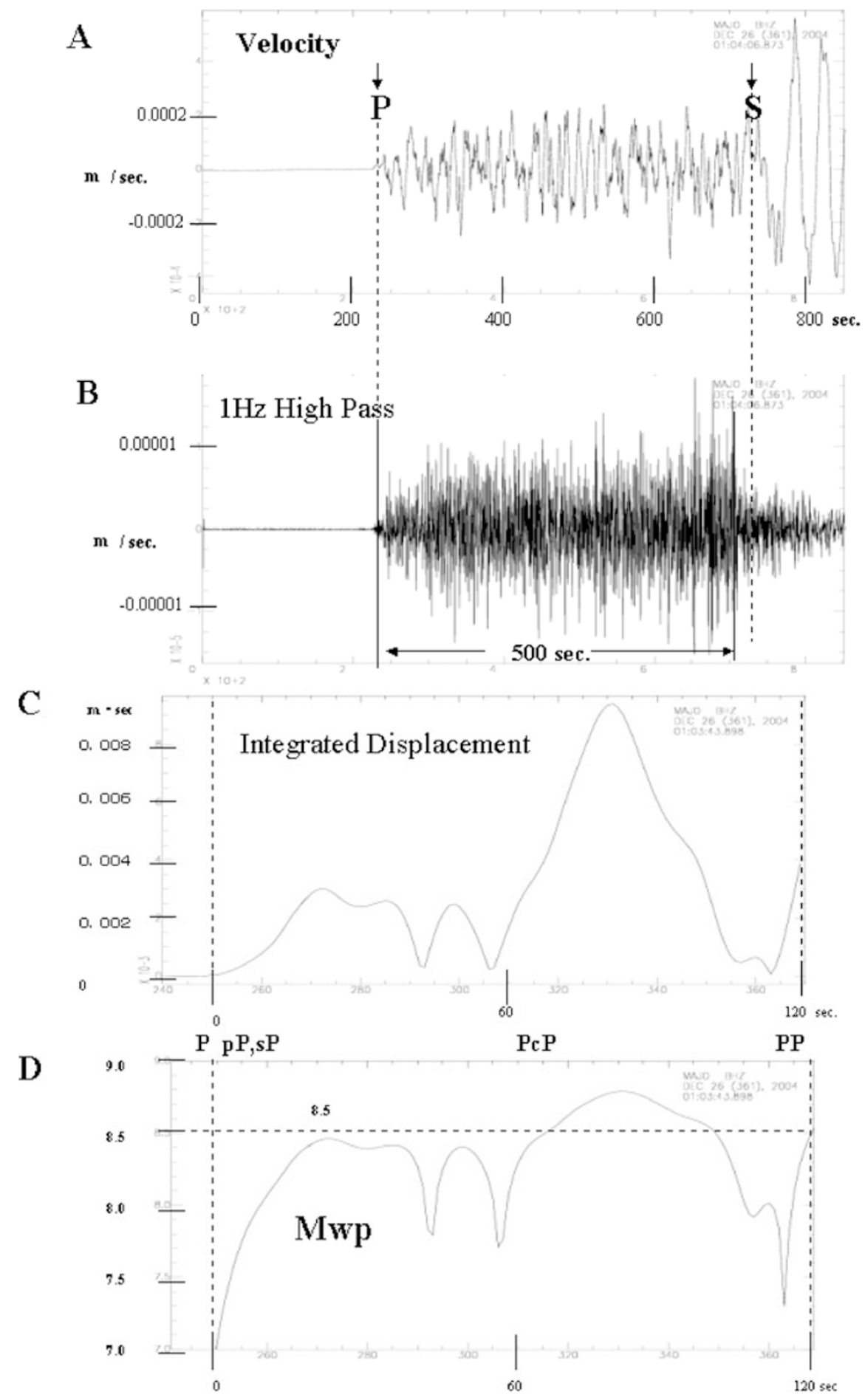

Fig. 3. M9.0 Sumatra-Andaman Island Earthquake on 26 December 2004. (A) Vertical component seismogram of velocity (m/sec.). (B) High frequency ( $1 \mathrm{~Hz}$ high-pass filtered) seismogram of velocity $(\mathrm{m} / \mathrm{sec}$.). Shorter wave trains are shown about 450 seconds which estimated as source duration. (C) Seismogram of the integrated displacement ( $\mathrm{m} \cdot \mathrm{sec}$.) in absolute values. Theoretical arrival time of $\mathrm{P}$ and later phases (pP, sP, PcP and PP) are shown. (D) Calculated Mwp from the integrated displacement seismogram.

central distance, and then shifted in time so that the P-wave arrival times appear in a vertical column. Superposition of a theoretical travel time curve over the data is then possible via an expansion/reduction of the amplitude/time axis. We then use a grid-search method and HYPOSAT/NORSAR to determine the hypocenter location. Our Grid-search method arranges the latitude, longitude, depth, and origin time in a 4 dimensional grid, and determine each initial value in every 5 degrees, $30 \mathrm{~km}, 60$ seconds and determine a final value by 0.01 degrees, $1 \mathrm{~km}$, a unit of 0.1 seconds by iteration of 18 times at the maximum (Furudate, 2002, 2003). Matsushiro Seismological Observatory of JMA determined the off west coast of Sumatra, Indonesia, OT $=2004 / 12 / 26$, 00:58:58 (UTC), $\mathrm{Mw}=8.8$ (3 stations), 3.49N, 95.91E, 


\section{5/03/28 MAJO(BHZ)}

A
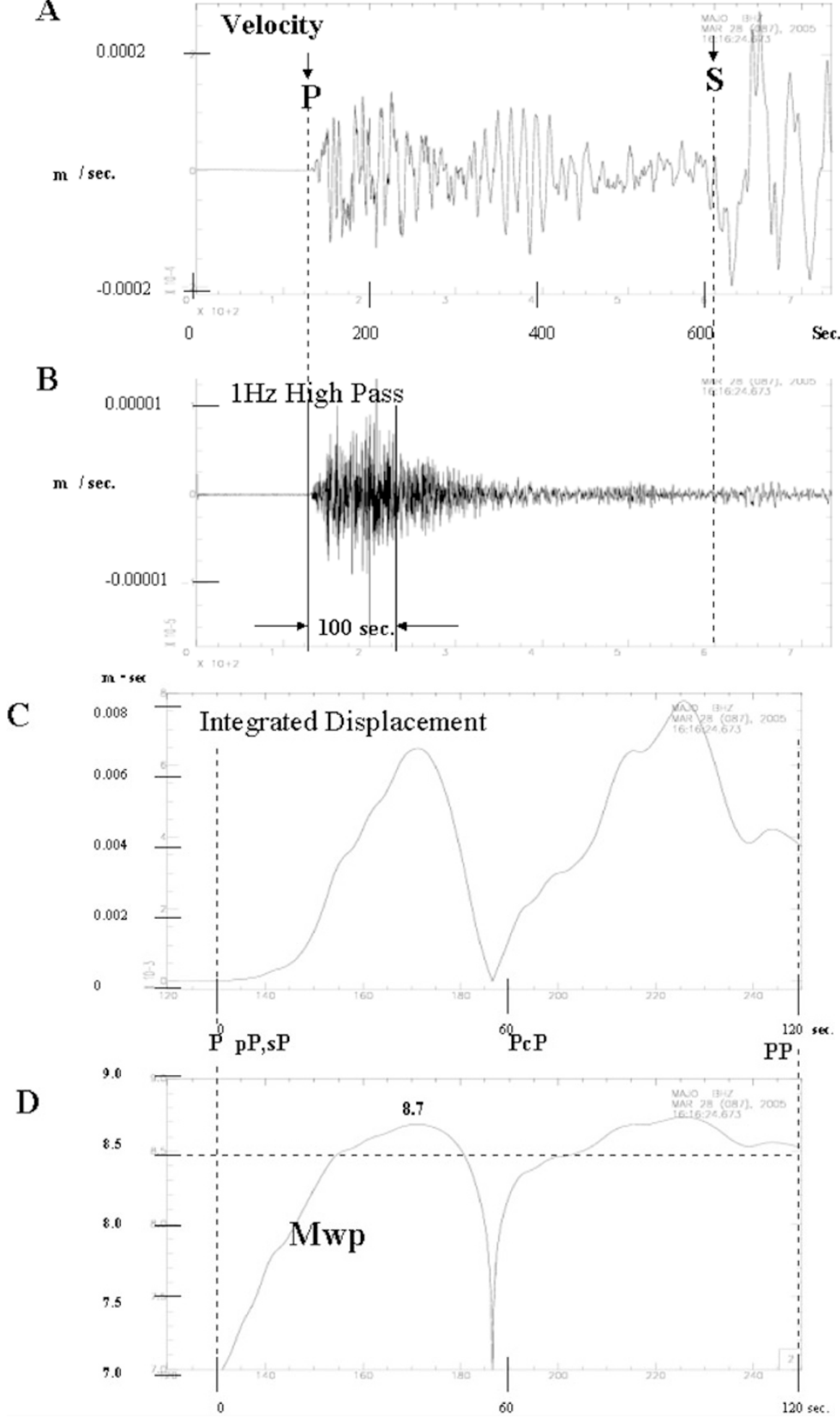

Fig. 4. M8.7 Northern Sumatra Island Earthquake on 28 March 2005. (A) Vertical component seismogram of velocity (m/sec.). (B) High frequency (1 Hz high-pass filtered) seismogram of velocity $(\mathrm{m} / \mathrm{sec}$.). Shorter wave trains are shown about 100 seconds which estimated as source duration. (C) Seismogram of the integrated displacement $(\mathrm{m} \cdot \mathrm{sec}$.) in absolute values. Theoretical arrival time of $\mathrm{P}$ and later phases (pP, sP, PcP and $\mathrm{PP})$ are shown. (D) Calculated Mwp from the integrated displacement seismogram.

$H=71 \mathrm{~km}$ and $3.49 \mathrm{~N}, 95.92 \mathrm{E}, 30 \mathrm{~km}$ (depth fixed) by Grid-search method and 3.41N, 95.85E, $H=0 \mathrm{~km}$ by HYPOSAT (Fig. 1). We determined the off west coast of Sumatra, Indonesia, OT = 2005/03/28, 16:09:31 (UTC), Mw = 8.7 (18 stations used), $1.94 \mathrm{~N}, 96.93 \mathrm{E}, H=0 \mathrm{~km}$ and
$1.93 \mathrm{~N}, 96.97 \mathrm{E}, 30 \mathrm{~km}$ (depth fixed) by Grid-search method and $1.93 \mathrm{~N}, 96.97 \mathrm{E}, H=7 \mathrm{~km}$ by HYPOSAT (Fig. 2). The Matsushiro Seismological Observatory (MSO) sends the hypocentral information for any earthquake larger than M6.5 to the JMA headquarter. Personnel at the JMA must 
then decide whether or not a tsunami has been generated by the earthquake. A moment magnitude of Mw8.8 for the December 2004 earthquake, was determined using the mean of four minutes of squared vertical velocity amplitudes starting from the P-wave arrival time (Ogahara et al., 2004). This complex event involved rupture of multiple seismic faults. In an effort to estimate moment magnitude more rapidly and precisely in near future, we therefore sought to improve the faster Mwp method for magnitude determination to make it more accurate for great earthquakes.

\section{Mwp}

Rapid, and precise evaluation of a potentially tsunamigenic earthquake's hypocenter and magnitude is important for saving lives from tsunami, and for reducing tsunami damage. The displacement of the P-wave portion observed on a vertical broadband seismograph record is theoretically considered as an approximate seismic source time function. The integrated displacement can then be viewed as representing the seismic moment as a function of time. We obtain the scalar seismic moment at each station from the vertical broadband record of the integrated displacement of the Pwave portion of the seismogram. The seismic moment $M o$ is obtained from the larger of the first peak (P1) of the Pwave portion of the seismogram, or the difference between $\mathrm{P} 1$ and the amplitude (P2) of $\mathrm{pP}$ or $\mathrm{sP}(\mathrm{P} 1-\mathrm{P} 2)$, on the integrated displacement record of the vertical broadband seismograph record (Tsuboi et al., 1995, 1999):

$$
M o=\max (|P 1|,|P 1-P 2|) \frac{4 \pi \rho \alpha^{3} r}{F^{p}}
$$

where $M o$ is the seismic moment, $\rho$ and $\alpha$ are the mean density and $\mathrm{P}$-wave velocity along the propagation path, $r$ is the epicentral distance, and $F^{p}$ is the p-wave radiation pattern. The moment magnitude is then obtained from

$$
M w=\frac{\log _{10} M o-9.1}{1.5}
$$

(Kanamori, 1977), for each vertical broadband seismic channel, without a correction for the radiation pattern. We add 0.2 to $\mathrm{Mw}$ obtained using the above procedure to compensate for to get Mwp. The results show that Mwp correlates well with Harvard's Mw's obtained from their Centroid Moment Tensor (CMT) solutions (Dziewonski et al., 1981). Both U.S. Tsunami warning centers, at the WC/ATWC and at the PTWC, use Mwp for their first estimate of Mw. It provides the fastest possible estimate of a large, potentially tsunamigenic earthquake's moment magnitude, enabling a fast Tsunami Warning. We calculated Mwp for both of these two great Sumatra earthquakes. In both cases, we analyzed 130 seconds of signal from the vertical component at MAJO beginning 10 seconds before the initial P-wave onset time. The velocity waveform (A), the $1 \mathrm{~Hz}$ high pass filtered velocity waveform (B), the absolute value of the integrated displacement waveform (C), and the Mwp value (D), are shown separately for the December 26, 2004 event in Fig. 3, and for the March 28, 2005 event in Fig. 4. From Eqs. (1) and (2) we calculated Mwp 8.0 for the December 26, 2004 event from the integrated displacement seismogram from MAJO. Using a magnitude correction of
(Mwp_initial-1.03)/0.83 (Whitmore et al., 2002), PTWC determined an Mwp from MAJO of 8.2. This value is still extremely small compared to Harvard's value for Mw of 9.0, and Stein and Okal's value of Mw 9.3. A scatterplot of 3748 individually determined Mwp deficits versus epicentral distance shows no obvious trend (Whitmore et al., 2002). Mwp deficit trend to epicenter distances is shown at MAJO for 18 events which determined the Mw greater than 7.0 by Harvard in the 2 years from 2003 to 2004 (Fig. 5). We then recalculated Mwp using $\alpha=0.16 \Delta+7.9 \mathrm{~km} . / \mathrm{sec}$. derived from a fit to the $\mathrm{P}$ wave apparent velocity from the IASP91 earth model instead of $\alpha=7.9 \mathrm{~km} / \mathrm{sec}$ ( $\mathrm{P}$ wave velocity) in Eq. (1); the original equation for Mwp. We determined Mwp = 8.5 from MAJO (Fig. 3D), and Mwp 8.6 from the average of 15 stations for the December 26, 2004 event, and Mwp 8.7 from MAJO (Fig. 4D), and Mwp 8.7 from the average of 15 stations for the March 28, 2005 event using the distance-dependent formulation for $\alpha$. Our new value of 8.5 for Mwp is still much smaller than Harvard's Mw of 9.0, and Stein and Okal's Mw of 9.3. The December 26, 2004 event was one of largest ever recorded, the rupture expanded at a speed of about 2.5 kilometers per second toward the north northwest, extending about 1,300 kilometers along the Andaman trough, composed of multiple fractures (Ammon et al., 2005). The value of Mwp 8.5 nearly equal to $\mathrm{Mw} 8.7(M o=0.16 \mathrm{E}+23 \mathrm{~N} \cdot \mathrm{m})$ estimated from the peak moment ratios $(4 \mathrm{E}+20 \mathrm{~N} \cdot \mathrm{m} / \mathrm{s})$ in a range of 120 seconds from P-wave arrival (Ammon et al., 2005). The value is large enough to be useful in evaluating the probability of tsunami generation. The duration of high frequency energy radiation more than 600 seconds ( $\mathrm{Ni}$ et al., 2005, Ishii et al., 2005). The high frequency durations are about 500, and 100 seconds respectively for the December 2004 and March 2005 events on 1 second highpass filtered broadband vertical velocity records from the IRIS MAJO station. These duration times show the differences between fracture lengths, and also provide an immediate estimate of the moment released from these events. The high frequency signal duration for the December 26, 2004 (Fig. 3B) event is about 500 seconds, as compared to

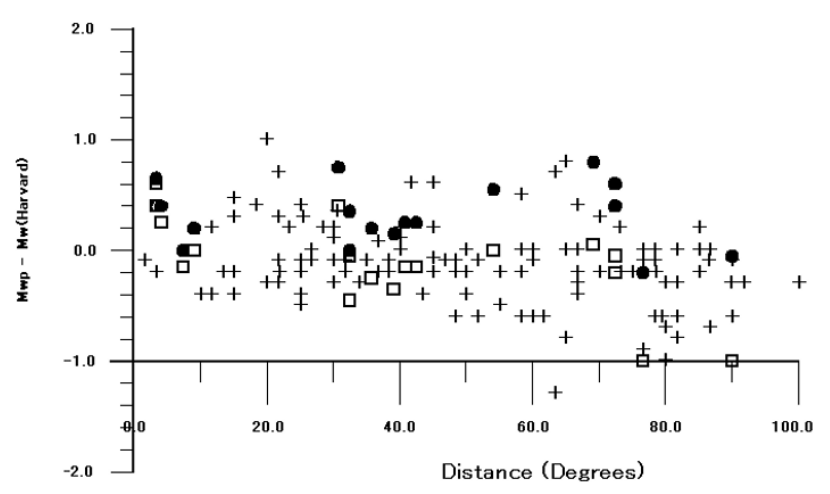

Fig. 5. Mwp deficit at MAJO plotted as a function of epicentral distance. Mwp deficit at MAJO is shown for 18 events which determined the Mw greater than 7.0 by Harvard in the 2 years from 2003 to 2004 (•: use the distance-dependent value of $\alpha=0.16 \Delta+7.9 \mathrm{~km} / \mathrm{sec}$ (correction), $\square$ : use the constant value of $\alpha=7.9 \mathrm{~km} / \mathrm{sec}$ (no correction), and +: scatterplot for the other stations (no correction). 
about 100 seconds for the March 28, 2005 (Fig. 4B) event. This difference reflects the propagation of the rupture front along different fault lengths (Ni et al., 2005).

\section{Summary}

The Matsushiro Seismological Observatory (MSO) of JMA uses the data from USGS LISS and IRIS BUD server to determine hypocenter and moment magnitude. The hypocenter is calculated by HYPOSAT/NORSAR and a Grid-search method developed in house at the MSO. We estimate moment magnitude from the mean of 4 minutes of vertical component broadband squared velocity amplitudes beginning at the P-wave arrival time. Using this method on data from the IRIS GSN station at MAJO, we estimate Mw values of 8.8 and 8.7 for the two events off of the North West Coast of Sumatra, Indonesia on December 26, 2004, and March 28, 2005 respectively. Both U.S. Tsunami warning centers (the WC/ATWC, and the PTWC) use Mwp to estimate moment magnitude, based in the integrated displacement amplitude of the vertical broadband P-wave portion of the seismogram. Mwp provides the fastest estimate of an of a large earthquake's moment magnitude enabling the Warning centers to issue a tsunami warning. The constant value for $\alpha$, the mean P-wave velocity along the propagation path was used in the original equation because Mwp was initially derived as a method for local earthquakes, using data from seismic stations within a few hundred kilometers of the epicenter. In this paper we use $\alpha=0.16 \Delta+7.9$ (the apparent P-wave velocity from a fit to the IASP91 earth model) instead of the constant value of 7.9 for $\alpha$ in the original equation for Mwp. This change gives a value for Mwp from the IRIS MAJO station of 8.5 (the PTWC's initial value for MAJO was 8.2), for the December 26, 2004 event, and a value of 8.7 (the PTWC's original value for MAJO was 8.4) for the March 28,2005 event. Mwp is not suitable for a precise estimate of the total moment magnitude of complex earthquakes, involving multiple fractures, such as the great December 26, 2004 Sumatra earthquake. Mwp does, however, provide the fastest possible moment magnitude estimate, and, using a distance-dependant $\mathrm{P}$-wave velocity, is accurate enough to justify an initial tsunami warning. Indeed, had a Sumatra type event occurred in the Pacific, the corrected Mwp discussed here would have well exceeded the tsunami regional watch/warning threshold used by PTWC and the WC/ATWC for the Pacific Basin.

Acknowledgments. The authors thank Barry Hirshorn for his critical reading in the manuscript. We would like to thank S. Weinstein and Y. Yoshida for careful reviews and constructive comments. SAC (Seismic Analysis Code) (Goldstein, 2005) was used for analysis of seismic waveform data.

\section{References}

Ammon, J. C., C. Ji, H.-K. Thio, D. Robinson, S. Ni, V. Hjorleifsdottir, H. Kanamori, T. Lay, S. Das, D. Helmberger, G. Ichinose, J. Polet, and D. Wald, Rupture process of the 2004 Sumatra-Andaman Earthquake, Science, 303, 1133-1139, 2005.

Dziewonski, A., M., T.-A. Chou, and J. H. Woodhouse, Determination of earthquake source parameters from waveform data for studies of global and regional seismicity, J. Geophys. Res., 86, 2825-2852, 1981.

Furudate, T., Utilization of LISS data, Tech. Rep. M.S.O.JMA, 19, 3-6, 2002.

Furudate, T., Utilization of LISS data and epicenter determination, Tech. Rep. M.S.O., JMA, 20, 17-22, 2003.

Goldstein, P., SAC (Seismic Analysis Code), http://www.llnl.gov/sac/, 2005.

Ishii, M., P. M. Shearer, H. Houston, and J. E. Vidale, Extent, duration and speed of the 2004 Sumatra-Andaman earthquake imaged by the Hi-net array, Nature, 435, 933-936, 2005.

Kanamori, H., The energy release in great earthquakes, J. Geophys. Res., 82, 2981-2987, 1977.

Lay, T., H. Kanamori, C. J. Ammon, M. Nettles, S. N. Ward, R. C. Aster, S. L. Beck, S. L. Bilek, M. R. Brudzinski, R. Butler, H. R. DeShon, G. Ekstrom, K. Satake, and S. Sipkin, The great Sumatra-Andaman earthquake of 26 December 2004, Science, 308, 1127-1133, 2005.

$\mathrm{Ni}, \mathrm{S} ., \mathrm{H}$. Kanamori, and D. Helmberger, Energy radiation from the Sumatra earthquake, Nature, 582, 2005.

Ogahara, T., T. Furudate, and M. Okada, Preliminary empirical formula to estimate moment magnitude of tele-seismic event by using LISS data, Tech. Rep. M.S.O., JMA, 21, 75-82, 2004.

Park, J., T. A. Song, J. Tromp, E. Okal, S. Stein, G. Roult, E. Clevede, G. Laske, H. Kanamori, P. Davis, J. Berger, C. Braitenberg, M. V. Camp, X. Lei, H. Sun, H. Xu, and S. Rosat, Earth's free oscillations excited by the 26 December 2004 Sumatra-Andaman earthquake, Science, 308, 1139-1144, 2005.

Stein, S. and E. Okal, Ultra-long period seismic moment of the great December 26, 2004 Sumatra earthquake and implication for the slip process, http://www.earth.northwestern.edu/people/seth/research/sumatra. html, 2005.

Tsuboi, S., K. Abe, K. Takano, and Y. Yamanaka, Rapid determination of Mw from broadband P waveforms, Bull. Seism. Soc. Am., 83, 606-613, 1995.

Tsuboi, S., P. M. Whitmore, and T. J. Sokolowski, Application of Mwp to deep and teleseismic earthquakes, Bull. Seism. Sic. Am., 89, 1345-1351, 1999.

Whitmore, P. M., S. Tsuboi, B. Hirshorn, and T. J. Sokolowski, Magnitudedependent correction for Mwp, Science of Tsunami Hazards, 20,4, 187192, 2002.

Yagi, Y., Preliminary results of rupture process for December 26, 2004 off coast of northern Sumatra giant earthquake (M9.0) (ver. 1), http://iisee.kenken.go.jp/staff/yagi/eq/Sumatra2004/Sumatra2004.html, 2005a.

Yagi, Y., Preliminary results of rupture process for March 28,2004 off coast of northern Sumatra giant earthquake (M8.7), http://iisee.kenken.go.jp/staff/yagi/eq/Sumatra2005/Sumatra20050328j.html, 2005b (in Japanese).

Yamanaka, Y., EIC Seismological note No.161+: Off the west coast of northern Sumatra earthquake (M9.0), http://www.eri.utokyo.ac.jp/topics/SUMATRA2004/index.html, 2005a.

Yamanaka, Y., EIC Seismological note No.164:Northern Sumatra earthquake (M8.7), http://www.eri.u-tokyo.ac.jp/topics/indonesia200503/ index-e.html, 2005b.

K. Kanjo (e-mail: kkanjo@met.kishou.go.jp), T. Furudate, and S. Tsuboi 